\title{
ПРАКТИЧЕСКИЕ РЕКОМЕНААЦИИ
}

\section{ПО АЕКАРСТВЕННОМУ АЕЧЕНИЮ}

\section{HЕМЕАКОКАЕТОЧНОГО РАКА АЕГКОГО}

Комлектив авторов: Горбунова В.А., Артамонова Е. В., Бредер В. В., Аактионов К. К., Моисеенко Ф.В., Реутова Е. В., Сакаева А.А.

DOI: 10.18027 / 2224-5057-2017-7-3s2-28-42

КАючевые слова: немелкоклеточный рак ^егкого, аАенокарцинома, неп^оскоклеточный рак ^егкого, плоскоклеточный рак мегкого, мутация EGFR, транслокация ALK, ROSI.

\section{I. ОПРЕАЕАЕНИЕ СТААИИ}

Классификация немелкоклеточного рака ^егкого (НMP^) по системе ТNM представлена в табл. І.

Таблица І. КАассификация немелкоклеточного рака ^егкого по системе TNM

\begin{tabular}{|c|c|c|c|}
\hline СтаАия & $\mathbf{T}$ & $\mathbf{N}$ & $M$ \\
\hline 0 & Tis & No & MO \\
\hline $\mathrm{IA}$ & Tla,b & No & MO \\
\hline IB & T2a & No & MO \\
\hline$\| \mathrm{A}$ & $\begin{array}{l}\text { Tla, b, 2a } \\
\text { T2b }\end{array}$ & $\begin{array}{l}\text { NI } \\
\text { No }\end{array}$ & MO \\
\hline$\| \mathrm{B}$ & $\begin{array}{l}\text { T2b } \\
\text { T3 }\end{array}$ & $\begin{array}{l}\text { NI } \\
\text { No }\end{array}$ & MO \\
\hline$\| I I A$ & \begin{tabular}{|l} 
T1,2 \\
T3 \\
T4
\end{tabular} & $\begin{array}{l}\mathrm{N} 2 \\
\mathrm{~N} 1,2 \\
\mathrm{~N} 0,1\end{array}$ & $\begin{array}{l}\text { MO } \\
\text { MO }\end{array}$ \\
\hline IIIB & \begin{tabular}{|l} 
T4 \\
Т ^юбая
\end{tabular} & $\begin{array}{l}\text { N2 } \\
\text { N3 }\end{array}$ & $\begin{array}{l}\text { MO } \\
\text { MO }\end{array}$ \\
\hline IV & Т ^юбая & $\mathrm{N}_{\text {^юбая }}$ & Mla,b \\
\hline
\end{tabular}

При проведении мекарственной терапии следует использовать современные подходы с целью обеспечения больных наиболее качественным и в то же время экономичным ^ечением. План лекарственной терапии Аолжен быть рассмотрен консилиумом специалистов с участием хирурга, химиотерапевта и ралиолога, а также при возможности морфолога и/или онкогенетика. Больные Аолжны быть

Цитирование: Горбунова В.А., Артамонова Е.В., Бредер В.В., Аактионов К. К., Моисеенко Ф. В., Реутова Е. В. и соавт. Практические рекоменАации по ^екарственному лечению немелкоклеточного рака ^егкого // Злокачественные опухоли : Практические рекоменАации RUSSCO \#3s2, 2017 (том 7). С. 28 -42. 
информированы о плане лечебно-Аиагностических мероприятий, выборе метолов ^ечения, возможных побочных реакциях и их влиянии на качество жизни.

Алгоритм лечебной тактики при различных морфологических типах, стаАиях болезни и молекулярно-биологических вариантах НМР^ преАставлен на рис.І .

\section{І. АИАГНОСТИКА}

Аиагноз НМРА основывается на Аанных анамнеза, осмотра, результатах инструментальных методов обследования и патоморфологическом заключении, установленном на основании морфологического исследования, материа^ А^я которого получен при биопсии или аспирате из первичной опухоли или метастатического очага (или экссуАата). ПреАпочтительна гистологическая (возможна и цитологическая) верификация Аиагноза. Следует стремиться к уточнению морфологической формы рака легкого - аАенокарцинома/п^оскоклеточный/крупноклеточный, при возможности с использованием ИГХ исслеАования.

При выявлении неплоскоклеточного (в том числе, Аиморфного) рака рекоменАовано провеАение молекулярно-генетических исслеАований (гистологический или цитологический материал) на наличие активирующих мутаций гена EGFR (19 и 21 экзоны) и транслокации ALK, ROSI. Молекулярно-генетическое тестирование может быть оправАано и в случаях п^оскоклеточного рака или при затруднении (ма^о материа^а) в опреАелении гистологического поАтипа у некурящих молоАых больных. Учитывая гетерогенность опухолей и появление новых мутаций, слеАует иметь ввиАу целесообразность повторных биопсий с целью изменения лечебной тактики. А^я назначения иммунотерапии пембролизумабом необходимо исслеАование экспрессии PD-LI опухолевыми клетками ^юбым валиАированным методом.

Возможность ХТ зависит от объективного состояния больного, распространенности процесса, наличия и выраженности сопутствующей патологии.

\section{I.I. Обследование}

Обслелование больного включает:

- сбор анамнеза и осмотр;

- кАинический анализ крови;

- биохимический анаАиз крови;

- коагулограмму;

- общий анахиз мочи;

- ЭКГ;

- R-графию и^и КТ органов груАной кАетки;

- ФБС;

- УЗИ органов брюшной полости и забрюшинного пространства, шейно-наАкАючичных зон (КТ выполняется А^я уточнения изменений, выявАенных при УЗИ); 
- РаАИонУкАиАнУю АИаГностику костей скелета c R-^огическим контролем выявАенных изменений;

- КТ/MPТ головного мозга с контрастным усилением по направлению невролога;

- биопсию опухоли с опреАелением морфологического типа HMP^;

- КТ органов груАной клетки и брюшной полости с контрастным усилением и^и ПЭТ/КТ

- МРТ головного мозга с контрастным усилением

- при подозрении на N2 - морфологическая верификация (трансбронхиа^ьная/трансэзофагеальная пункция, меАиастиноскопия, торакоскопия); при невозможности получения биопсийного материа^а - ПЭТ/КТ А^я оценки распространенности опухолевого процесса;

- молекулярно-генетическое исследование и определение биомаркеров в опухоли: наличие активирующих мутаций EGFR, транслокации гена ALK, ROSI, экспрессии PD-LI.

- C целью прогнозирования возможных Аальнейших опций таргетной терапии у больных с генетическими изменениями и определения частоты Аанных изменений в Российской популяции рекоменАуется после опреАеления активирующих мутаций и экспрессии PD-LI тестирование на мутацию BRAF V600E, MET амплификацию или мутацию в 14 экзоне, RET реаранжировку, мутацию HER2 и KRAS.

\section{2. АЕЧЕНИЕ}

\section{I. Локахизованные стаАии}

\section{I.I. ААъювантная терапия}

\section{I.I.I. Общие принципы аАъювантной терапии}

ААъювантная ХТ проводится в Аополнение к локальным (хирургическому и лучевому) метолам лечения и позволяет снизить риск рецилива болезни. При планировании аАъювантной ХТ необхолимо оценить стаАию заболевания, прогноз, ожилаемую пользу, сопутствующие заболевания, возможные осложнения и их влияние на качество жизни, а также учесть предпочтения пациента. Возраст сам по себе не яв^яется ограничением при отсутствии противопоказаний из-за сопутствующих заболеваний.

При опухолях небольших размеров в сочетании с отсутствием региональных метастазов, являющихся прогностически благоприятными, аАъювантная ХТ облалает минима^ьной эффективностью. 
При проведении аАъювантной ХТ слеАует использовать станАартные режимы с соблюАением оптима^ьной Аозовой интенсивности, по возможности избегать необоснованных реАукций Аоз препаратов, увеличения интервалов межАу курсами, уменьшения числа курсов. После раАикальных операций, начиная с IB стаАии НМРА, показано проведение аАъювантной XТ, которая улучшает безрециливную и общую 5-летнюю выживаемость. ААъювантную XТ начинают не позАнее 8 неА. после операции при восстановлении пациента (ECOG 0-I). Могут быть использованы ^юбые п^атиносодержащие комбинации с вк^ючением химиопрепаратов III поколения или этопозила, всего проводится 4 цикла лечения. Наиболее изученными и часто применяемыми комбинациями яв^яются сочетания винорелбина и цисплатина, гемцитабина и цисплатина, паклитаксела и карбоплатина. При неп^оскоклеточном НМР^ оправАано применение режима пеметрексеА + цисплатин. При противопоказанияхк назначению цисплатина можно использовать карбоплатин. Таргетная терапия в аАъювантном режиме не проводится. Рекоменауемые режимы аАъювантной ХТ преАставлены в таб^. І. Послеоперационная $А T$ у больных с R0 резекцией не проводится. В случае невозможности проведения/отказа от хирургического лечения и/или АТ па^лиативную ХТ применяют как самостоятельный виА (см. разАел 2.3).

\section{I.I.2. Показания к провеАению аАъювантной химиотерапии}

IА СТААИЯ

ААъювантная ХТ не показана.

IB СТААИЯ

Показано наблюление или аАъювантная XТ А^я группы высокого риска у больных в возрасте моложе 75 лет: опухоли >4 см, вовлечение висцеральной плевры, сосуАистая инвазия, низкая степень Аифференцировки, хирургическое лечение в объеме атипичной резекции, $\mathrm{Nx}$.

\section{II-IIIA CTAАИИ}

При II сталии заболевания в случае невозможности хирургического лечения проводится химиолучевая терапия, или АТ, или химиотерапия.

При исходно не резектабельной опухоли у больных в УАовлетворительном общем состоянии (по шка^е ECOG 0-І ба^^) на первом этапе проводится оАновременная химиолучевая терапия; при состоянии по шкале ECOG 2 бал^а преАпочтительнее последовательное использование Авух метоАов: АТ с послеАующими 3-4 консолиАирующими курсами ХT.

НеоаАъювантная ХТ химиотерапия (2 курса) может рассматриваться у пациентов с IIIA стадией за счет N2 (Аоказанного морфологически и^и при ПЭТ/КТ) в качестве этапа комбинированного лечения. Операцию необходимо выполнять не позАнее 3-4 неАель от послеАнего ввеАения химиопрепаратов. 
ААъювантная химиотерапия назначается во всех случаях $\mathrm{N}+$ при отсутствии противопоказаний. Следует учитывать ослабленное состояние больных после операции.

Таблица І. РекоменАуемые режимы аАъювантной и неоаъювантной химиотерапии немелкоклеточного рака ^егкого

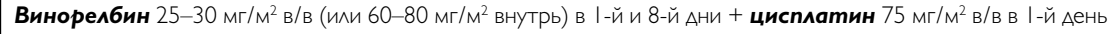
I раз в 3 неА.; АО 4 циклов

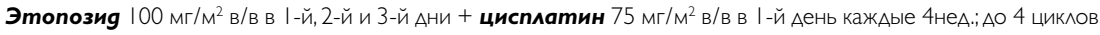

Паклитаксел 175-200 мг/м² в/в в I-й Аень + карбоплатин AUC 5-6 в/в В I-й Аень кажАые 3 неА;; АО 4 циклов

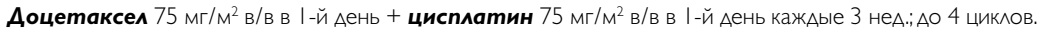

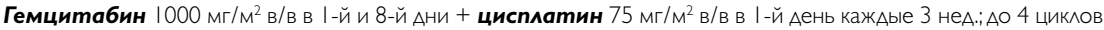

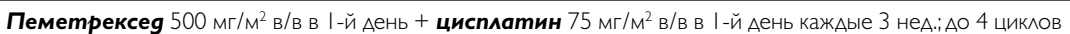
с премеАикацией фолиевой кислотой и витамином ВI2 за 5-7 Аней Ао начала кажАого цикла (только неп^оскоклеточный НМРА)

\section{2. Местнораспространенная (IIIB) стаАия}

Химиолучевая терапия является станАартным поАХодом при лечении больных местнораспространенным (не операбельным) НМР^.

ОАновременная химиолучевая терапия Аает лучшие результаты по сравнению с послеАовательной, оАнако она более токсична и провоАится только больным в УАовлетворительном общем состоянии (по шкале ECOG 0-І ба^^). При состоянии по шкале ECOG 2 преАпочтительнее последовательное применение химио- и лучевой терапии. Планируемая СОА Аолжна быть не менее 60 Гр.

Оптима^ьный объем ХТ в составе химиолучевой терапии - еженелельное введение паклитаксела и цисплатина/карбоплатина. При невозможности использовать эти комбинации возможно применение комбинации этопозиАа и цисплатина/карбоплатина в еженеАельном режиме. Возможно применение стандартной химиотерапии (паклитаксел + карбоплатин I раз в 3 нелели, пеметрексеА + цисплатин I раз в 3 неАели) оАновременно с $А$.

При IIIB стаАии стандартно используют Авухкомпонентные платиновые комбинированные режимы ХТ (табл. 2). При противопоказаниях к химиолучевому лечению проводится системная ХТ (см. раздел 2.3.).

Таблица 2. Рекоменауемые режимы химиотерапии немелкоклеточного рака ^егкого IIIA, В стаАий в комбинации с кучевой терапией

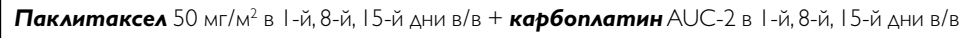

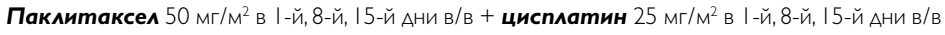

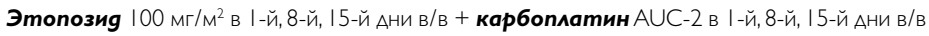

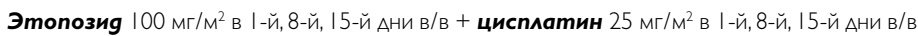




\section{3. Метастатическая (IV) стаАия}

Аечение больных IV сталией НMP^ следует расценивать только как па^лиативное. Оно может увеличивать продолжительность жизни, улучшать ее качество и эффективно контролировать симптомы болезни. Раннее начало подАерживающей и сопроводительной симптоматический терапии увеличивает проАолжительность жизни. Аечение назначается с учетом преАиктивных и прогностических факторов. А^горитм ^ечения HMP^ IV стадии преАставлен на рис. I-4.

\section{3.І. Молекулярно-генетическое тестирование и опрелеление биомаркеров}

Гистологический вариант опухоли и молекулярно-генетические характеристики являются важными факторами выбора варианта лечения. При выявлении активирующих мутаций гена EGFR (19 и 21 экзоны) или транслокаций ALK и ROSI оптима^ьным яв^яется назначение таргетной терапии. При отсутствии Арайверных молекулярно-генетических нарушений слеАует иметь в виАу возможность новой опции лечения распространенного НМРА - иммунотерапии (пембролизумабом), Аля чего необхолимо исследование экспрессии PD-LI опухолевыми клетками с использованием валилированного теста; при назначении ниволумаба во второй линии терапии исслеАования экспрессии PD-LI не требуется (см. разАе^ 2.3.2.I). В остальных случаях проводится ХТ (см. разАел 2.3.2.2).

\subsection{2. Аекарственная терапия I ^инии}

\subsubsection{I. Молеку^ярно-направленная терапия EGFR (+), ALK/ROSI (+) немелкоклеточного рака ^егкого}

- А^я пациентов с мутациями гена EGFR в 19 или 21 экзонах в качестве терапии I ^инии слеАует рассматривать ингибиторы тирозинкиназы EGFR (гефитиниб, эр^отиниб, афатиниб). При выявлении мутации EGFR в 19 (Del) экзоне назначение афатиниба в I линии ^ечения позволяет увеличить общую выживаемость в сравнении с химиотерапией. Если мутация EGFR выявлена после начала XT I ^инии, XТ целесообразно завершить (при эффективности - после 4 курсов) и перейти на лечение ингибиторами тирозинкиназы EGFR (рис. 3).

- При транслокации ALK/ROSI (методы Аиагностики - FISH, ИГX, ПЦР) оптимальным режимом I первой минии лечения яв^яется кризотиниб по 250 мг 2 раза/сут. Ао кАинического прогрессирования или непереносимой токсичности. При выявлении транслокации ALK после начала I ^инии XT возможно ее проАолжение Ао 4 цик^ов с послеАующим перехоАом на лечение кризотинибом; в отАельных случаях возможно Аинамическое наблюАение Ао прогрессирования с послеАующим началом терапии кризотинибом (рис. 4). 
- Молекулярно-направленная терапия может быть назначена ослабленным больным (общее состояние по шкале ECOG 3-4 бал^а), имеющим в опухоли соответствующую молекулярную мишень.

- Молекулярно-направленная (таргетная) терапия проводится непрерывно Ао появления клинических признаков прогрессирования процесса. ОАнако при ^ока^ьном прогрессировании (олигометастатический процесс, например в го^овном мозге) оправАано и возможно продолжение лечения ингибиторами тирозинкиназ с оАновременной АТ (стереотаксической или раАиохирургией) или хирургическим УАалением солитарного очага (рис. 3 и 4).

- Периоличность обслелования больныхв процессе молекулярно-направленной терапии - I раз в 3 мес. или по клиническим показаниям. Аечение проводится Ао прогрессирования заболевания и при бессимптомном прогрессировании может быть продолжено Ао появления симптомов заболевания. Режимы молекулярно-направленной терапии представлены в табл. 3.

\subsubsection{2. Химиотерапия}

Наиболее эффективны Авухкомпонентные химиотерапевтические режимы на основе производных платины в комбинации с этопозиАом, виноре^бином, гемцитабином, таксанами, пеметрексеАом (послеАний - только при неплоскоклеточном HМР^). Комбинация пеметрексеАа с цисплатином у больных неп^оскоклеточным НМРА в ранАомизированном исслеАовании показала преимущество по сравнению с комбинацией с гемцитабином.

Неплатиновые комбинации могут быть использованы в том случае, если назначение производных платины противопоказано.

Бевацизумаб (в сочетании с ХT) назначается только при неплоскоклеточном раке без инвазии в магистральные сосуды больным в уАовлетворительном общем состоянии без кровохаркания и применяется Ао прогрессирования процесса.

А^я ^ечения пожилых пациентов или больных в общем состоянии по шкале ECOG 2 балма в качестве минимального варианта ^ечения может быть рекоменАована монотерапия [этопозиА, виноре^бин внутрь или в/в, пеметрексеА (неп^оскоклеточный НMPА), таксаны, гемцитабин] или комбинация этих препаратов с производными платины (оптима^ьный вариант) при переносимости.

При контроле роста опухоли (стабилизация, полная или частичная регрессия) проводятся 4 курса XТ, в случае нарастающего объективного эффекта число курсов может быть увеличено Ао 6 с послеАующим Аинамическим наблюАением (обслеАование каждые 3 мес.). Оценка эффективности лечения проводится каждые 2 курса химиотерапии.

В случае метастатического поражения костей (литического и смешанного характера) назначаются бисфосфонаты или Аеносумаб (оптима^ьно), при угрозе перелома либо с обезболивающей целью рекомендуется палмиативная АТ.

При крупноклеточном нейроэнАокринном раке вариантом выбора является комбинация этопозиА + цисп^атин. 


\subsubsection{3.Иммунотерапия}

В качестве иммунотерапии I линии применяется анти-PD-I МКА пембро-

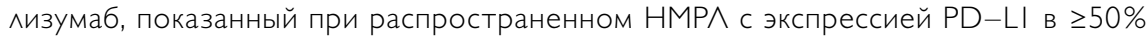
опухолевых клеток при отсутствии мутаций в генах EGFR или транслокации ALK/ROSI. Пембролизумаб назначают в дозе 200 мг в/в 30 мин. кажАые 3 неА.

Рекоменауемые режимы лекарственной терапии I ^инии метастатического НМР^ преАставлены в таб^. 3.

Таблица 3. Рекоменауемые режимы ^екарственной терапии I ^инии немелкоклеточного рака ^егкого IV стаАии

\section{Химиотерапия}

Эmonозиg 100 мг/м² в/в в I-3-й Ани + кар6опматин AUC-5 в/в в I-й день кажАые 3 неА., 4-6 курсов

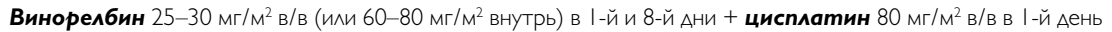
каждые 3 неА., 4-6 курсов

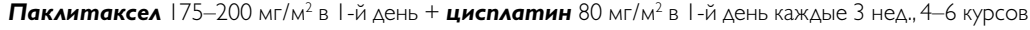

Паклитаксел 175-200 мг/м² в/в в I-й Аень + карбопматин AUC 5-6 в/в в I-й Аень кажАые 3 неА., 4-6 курсов +/- бевацизума6 7,5 мг/кг в/в I раз в 3 неА. АО прогрессирования

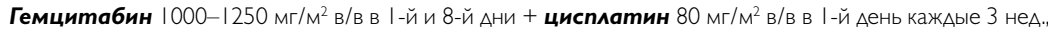
4-6 курсов

Гемцитабин | 000-1250 мг/м² в/в в |-й и 8-й Ани + цисплатин 40 мг/м² в |-й и 8-й Ани кажАые 3 неА., 4-6 курсов

Гемцитабин 1000 мг/м² в/в В I-Й и 8-й Ани + карбоплатин AUC5 в/в в I -й Аень кажАые 3 неА.,4-6 курсов

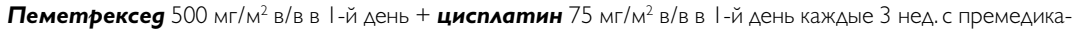
цией фолиевой кислотой и витамином ВІ2 за 5-7 Аней Ао начала курса, всего 4-6 курсов +/- бевацизума6 7,5 мг/кг в/в I раз в 3 неА. АО прогрессирования

Винорелбин 25-30 мг/м² в/в (или 60-80 мг/м² внутрь) в I-й, 8-й, I5-й Ани кажАые 4 неА. или 25-30 мг/м² в/в (или 60-80 мг/м² внутрь) в І -й и 8-й день кажАые 3 неА., 4-6 курсов

Эmonoзиg 120 мг/м² в/в в |-й, 2-й, 3-й Ани кажАые 3 неА., 4-6 курсов

Гемцитабин 1000-1250 мг/м² в/в в І-й и 8-й Ани кажАые 3 неА., 4-6 курсов

Аоцетаксел 75 мг/м² в/в в I-й день каждые 3 неА. 4-6 курсов

Пеметрексеg 500 мг/м² в/в в I-й Аень кажАые 3 неА. с премеАикацией фолиевой кислотой и витамином В।2 за 5-7 Аней Ао начала курса

\section{Таргетная терапия}

Гефитиниб по 250 мг внутрь ежеАневно Амительно при наличии активированных мутации EGFR Эрмотини6 по I50 мг внутрь ежеАневно Алительно при наличии активированных мутаций EGFR

Афатини6 по 40 мг внутрь ежеАневно Алительно при наличии активированных мутаций EGFR

Кризотиниб по 250 мг 2 раза/сут. внутрь Алительно при мутацияхALK и ROSI

\section{Иммунотерапия}

Пембролизумаб 200 мг в/в 30-минутная. инфузия кажАые 3 неА. Аля пациентов с экспрессией PD-LI в $\geq 50 \%$ опухолевых клеток 


\subsubsection{4. ПоААерживающая терапия}

При стабилизации или регрессии после 4-6 курсов ^ечения заболевания может быть проАолжена поАлерживающая терапия с учетом токсичности и эффективности. В качестве проАолженной поААерживающей терапии возможно применение пеметрексеАа, бевацизумаба или их комбинации (все опции - при неп^оскок^еточном НMP^) или гемцитабина, если эти препараты вхоли^и в схему лечения.

\subsection{3. Аекарственная терапия II минии}

Выбор терапии II ^инии зависит от того, какие препараты и с каким эффектом были использованы ранее, и может уменьшать выраженность симптомов рака ^егкого, а также увеличивать проло^жительность жизни. Эта терапия Аолжна назначаться только при прогрессировании опухолевого процесса. Оценка эффекта выполняется кажАые 6-8 неА., преАпочтительный метоА - КТ.

\subsection{3.І. Немелкоклеточный рак ^егкого без активирующих мутаций}

Пациентам в общем уАовлетворительном состоянии (по шкале ECOG 0-I бал^) возможно назначение платиновых комбинаций, ослабленным больным (состояние по шкале ECOG 2 ба^^а) - монотерапии пеметрекседом, гемцитабином или винорелбином Ао клинического прогрессирования, если эти препараты не использовались в I ^инии. ПреАпочтительным является назначение ингибиторов контрольных точек иммунитета анти-PD-I МКА ниволумаба или пембролизумаба в том случае, если пембролизумаб не был использован в I ^инии лечения:

- ниволумаб рекоменауется в Аозе 3 мг/кг в/в 60-минутная инфузия кажАые 2 неА. у больных плоскоклеточным и неплоскоклеточным НМРА;

- пембролизумаб рекоменауется в дозе 2 мг/кг кажАые 3 неА. у больных плоскоклеточным и неплоскоклеточным HMP^ с экспрессией PD-LI в $\geq 1 \%$ опухолевых клеток.

У больных аленокарциномой с прогрессированием в течение 6 мес. от начала XТ I ^инии преАпочтительным яв^яется назначение Аоцетаксела (если он не применялся ранее) в комбинации с нинтеАанибом.

\subsubsection{2. При невозможности опреАеления активирующих мутаций гена EGFR как при аАенокарциноме, так и при п^оскокАеточном раке мегкого}

Оправлана попытка молекулярно-направленной терапии эрлотинибом, гефитинибом или афатинибом. При эффективности/стабилизации болезни лечение может быть проАолжено Ао к^инического прогрессирования. 


\subsubsection{3. Немелкоклеточный рак Аегкого с Арайверными мутациями (EGFR, ALK, ROSI) и прогрессированием на фоне таргетной терапии}

Необхолимо опреАелить характер прогрессирования: системное, инАо^ентное и^и ^окальное (олигопрогрессия).

- Системное прогрессирование, состояние по шкале ECOG 0-I:

- оценить возможность ребиопсии с послеАующей сменой ^ечения и перевоАом на химиотерапию платиновым Аублетом (+/- бевацизумаб) или Аоцетаксе^ом (+/- бевацизумаб) или Аоцетакселом в комбинации с нинтеАанибом. После окончания XT II ^инии возможно продолжение приема ингибиторов тирозинкиназ EGFR при поАтвержАении исхоАной активирующей мутации и отсутствии мутации Т790М по Аанным ребиопсии; в этом случае у больных с Аелецией в 19-м экзоне EGFR после прогрессирования на фоне приема ингибиторов тирозинкиназ первого поколения возможен перевоА на афатиниб.

- у больных с активирующими мутациями EGFR назначение во II минии ингибиторов контрольных точек иммунитета не увеличивает общую выживаемость по сравнению с Аоцетакселом, однако эти Аанные получены из подгрупповых анализов, вк^ючающих небольшое число пациентов; иммунотерапия анти-PD-I MKА не уступает монотерапии Аоцетакселом по эффективности и имеет преимущества по переносимости в этой поАгруппе.

- Индолентное прогрессирование: продолжение таргетной терапии тем же ингибитором тирозинкиназы.

- Олигопрогрессия: продолжение таргетной терапии тем же ингибитором тирозинкиназы + ^окальный виА лечения.

\subsubsection{4. Немелкоклеточный рак ^егкого с Арайверными мутациями (EGFR, ALK, ROSI) и прогрессированием на фоне ияи после химиотерапии I Аинии}

Назначение соответствующего молекулярно-направленного препарата во II линии. III и IV ^инии терапии могут быть назначены пациентам в уАовлетворительном общем состоянии (по шкале ECOG 0-I ба^^) при наличии не использованных ранее лечебных опций.

\subsection{4. Палмиативная мучевая терапия}

Используется на ^юбых этапах заболевания А^я ^окального контроля со^итарных метастазов, Аля симптоматического лечения (болевой синАром, кровохаркание, обструкция). 


\subsection{5. Метастазы в головном мозге}

Частое проявление прогрессирования рака легкого, в основном - аАенокарциномы (Ао 30\%). При выявлении одиночных солитарных метастазов ма^ого размера (менее 30 мм) возможно ^окальное лечение: оперативное уааление и/или ^Т (на весь головной мозг в РОА 2,5-3 Гр, СОА 30 Гр) и/и^и стереотаксическая АТ или радиохирургическое лечение с послеАующей крупнопольной $А Т$ на головной мозг.

При бессимптомном метастатическом поражении вещества мозга лечение может быть начато с ХТ. Симптомные метастазы в головном мозге могут быть показанием к нейрохирургическому ^ечению на первом этапе с послеАующей химиолучевой терапией. Высокие Аозы ГКС (Аексаметазон Ао 24 мг/сут.) - обязательный компонент симптоматического ^ечения, направленного на уменьшение отека вещества мозга; при неэффективности ГКС в рекоменАованной Аозе Аальнейшее повышение Аозы неэффективно и свиАетельствует о неблагоприятном прогнозе.

Развитие метастазов в головном мозге на фоне эффективной таргетной терапии (гефитиниб, эр^отиниб, афатиниб, кризотиниб) может свилетельствовать об особенностях фармакокинетики препаратов - п^охой проницаемости гематоэнцефалического барьера; в таком случае целесообразно проведение $А Т$ на головной мозг и продолжение таргетного лечения. 

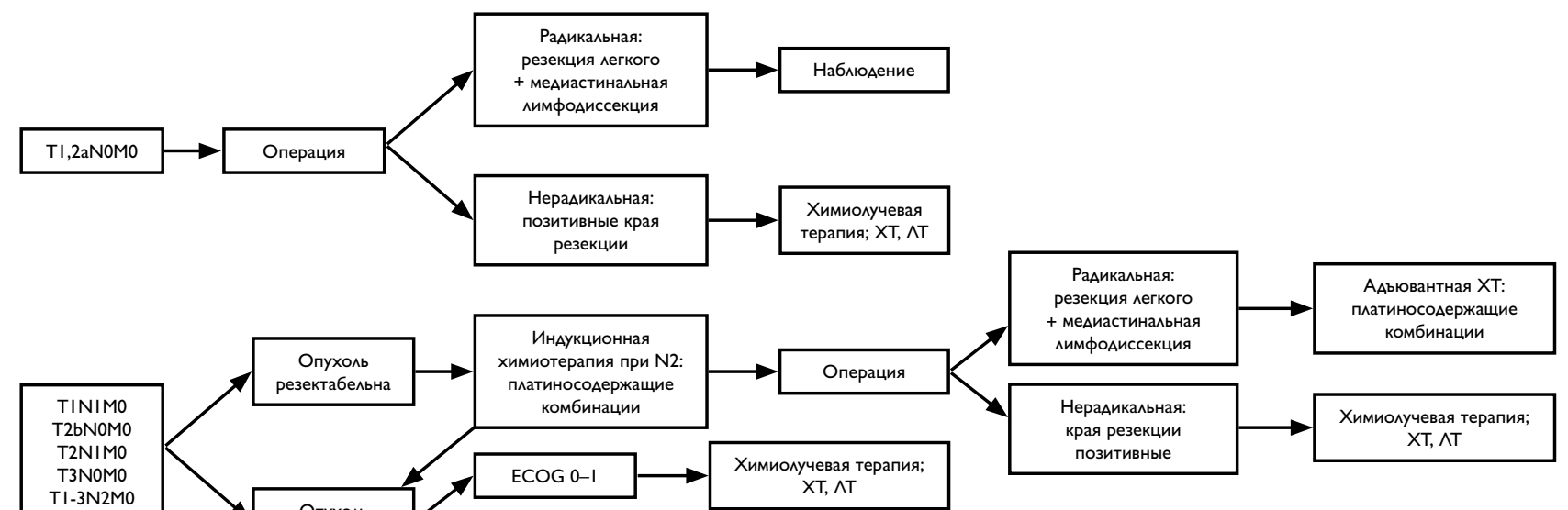

TI-3N2M0

Опухоль

нерезектабельна

Последовательно

$\mathrm{XT} \rightarrow \wedge \mathrm{T}, \mathrm{XT}, \wedge \mathrm{T}$

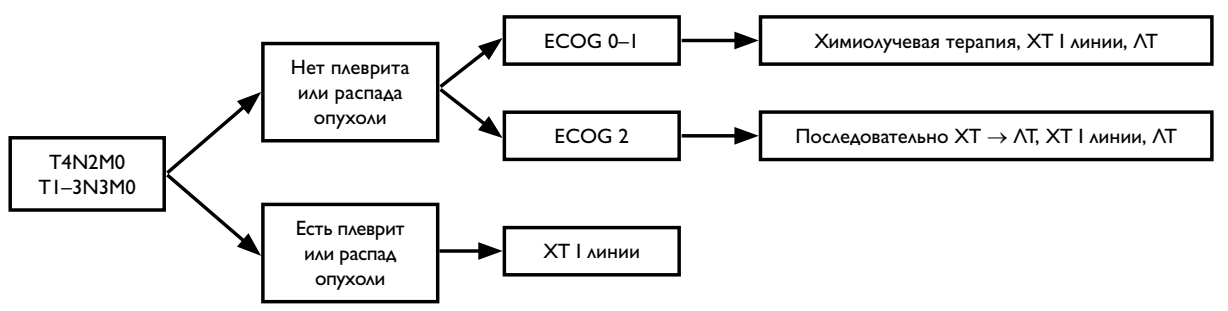



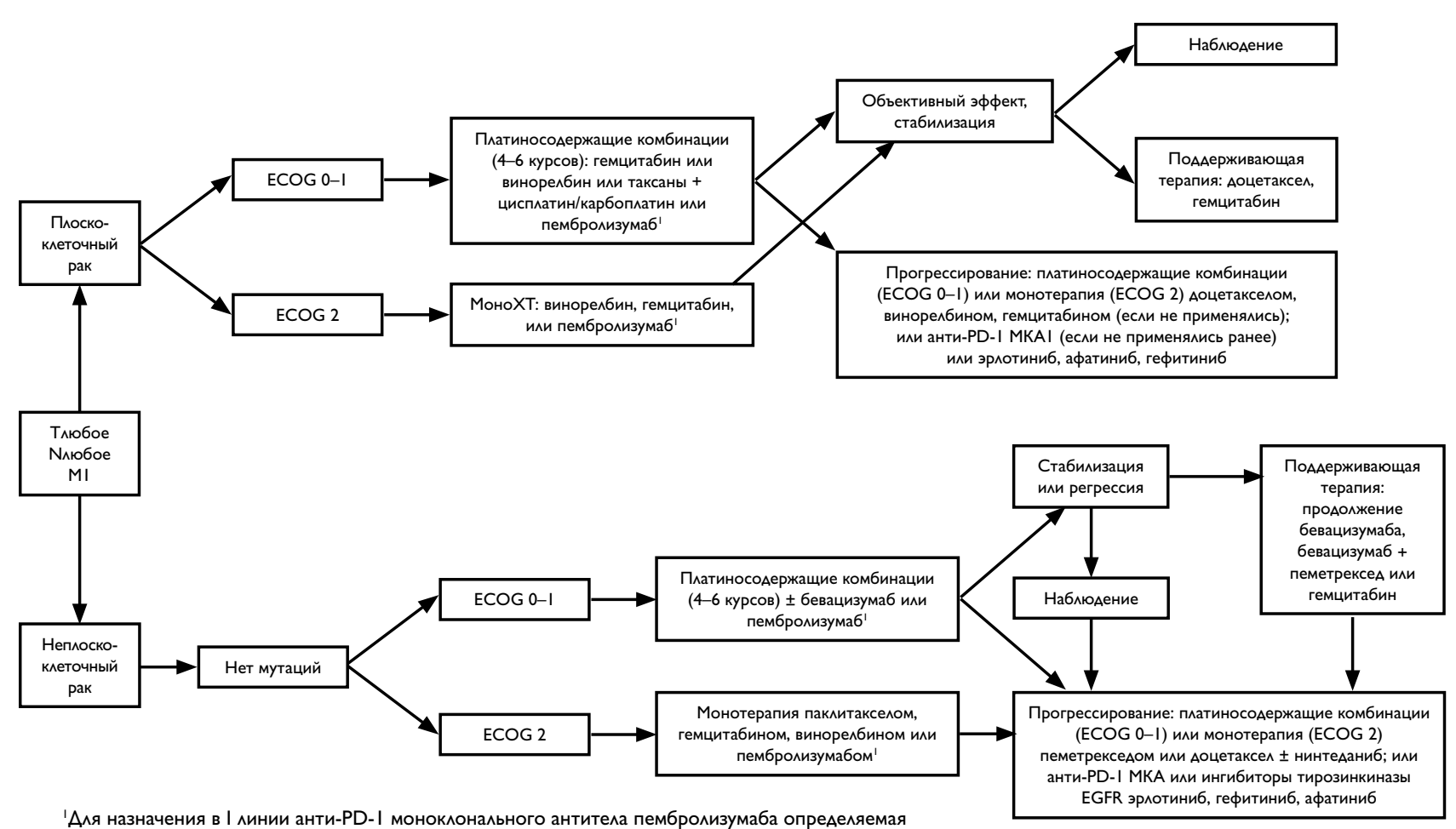
ваАиАированным тестом экспрессия РD-L АОмжна быть $\geq 50 \%$, во 2-й Аинии - $\geq 1 \%$. ВвоАимая в 3 неАели Аоза пембролизумаба в І линии терапии составляет 200 мг, во ІІ минии - 2 мг/кг веса 
ПЕРВАЯ АИНИЯ

ПОСАЕАУЮЩАЯ ТЕРАПИЯ

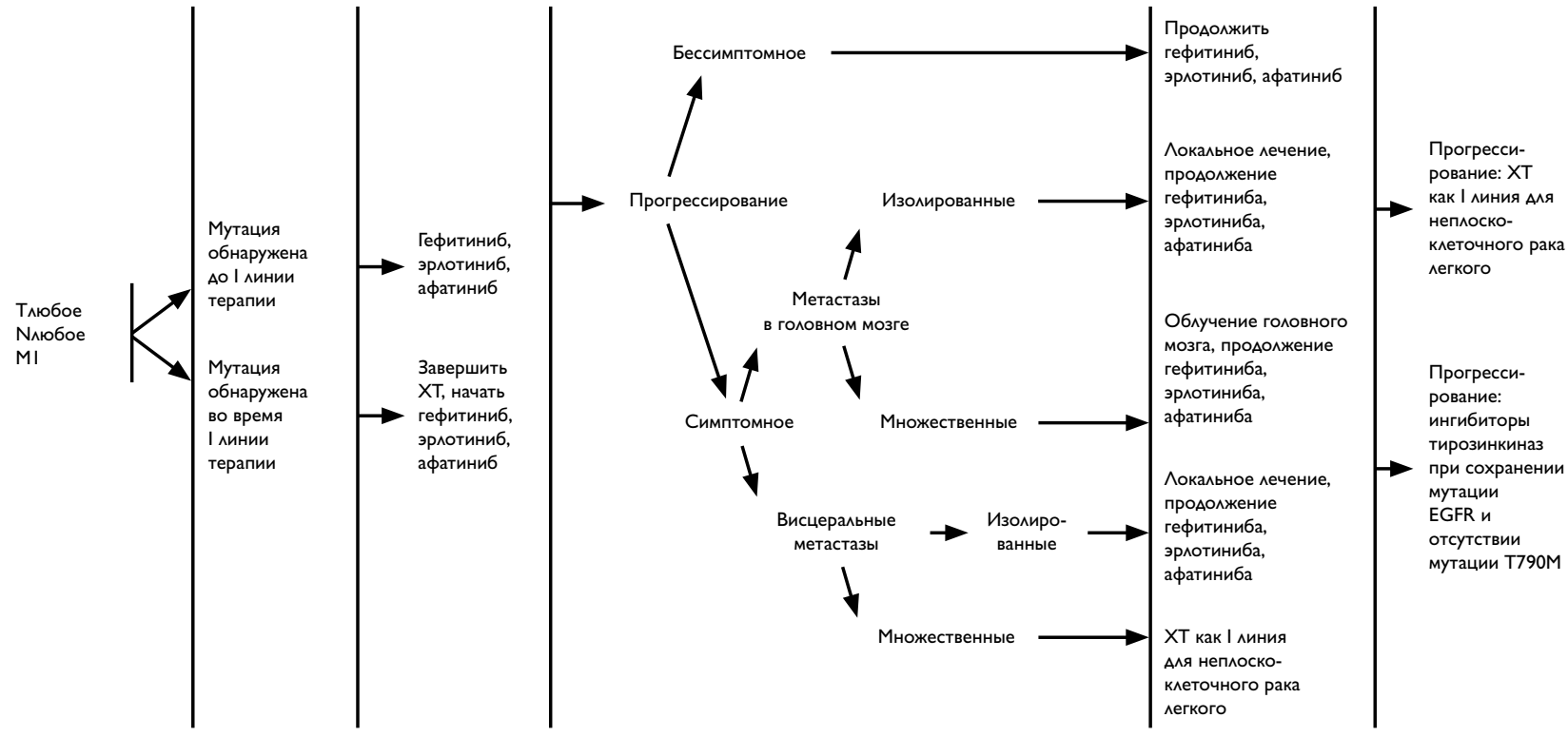

Периодичность обследования - кажАые 3 мес. или по клиническим показаниям 


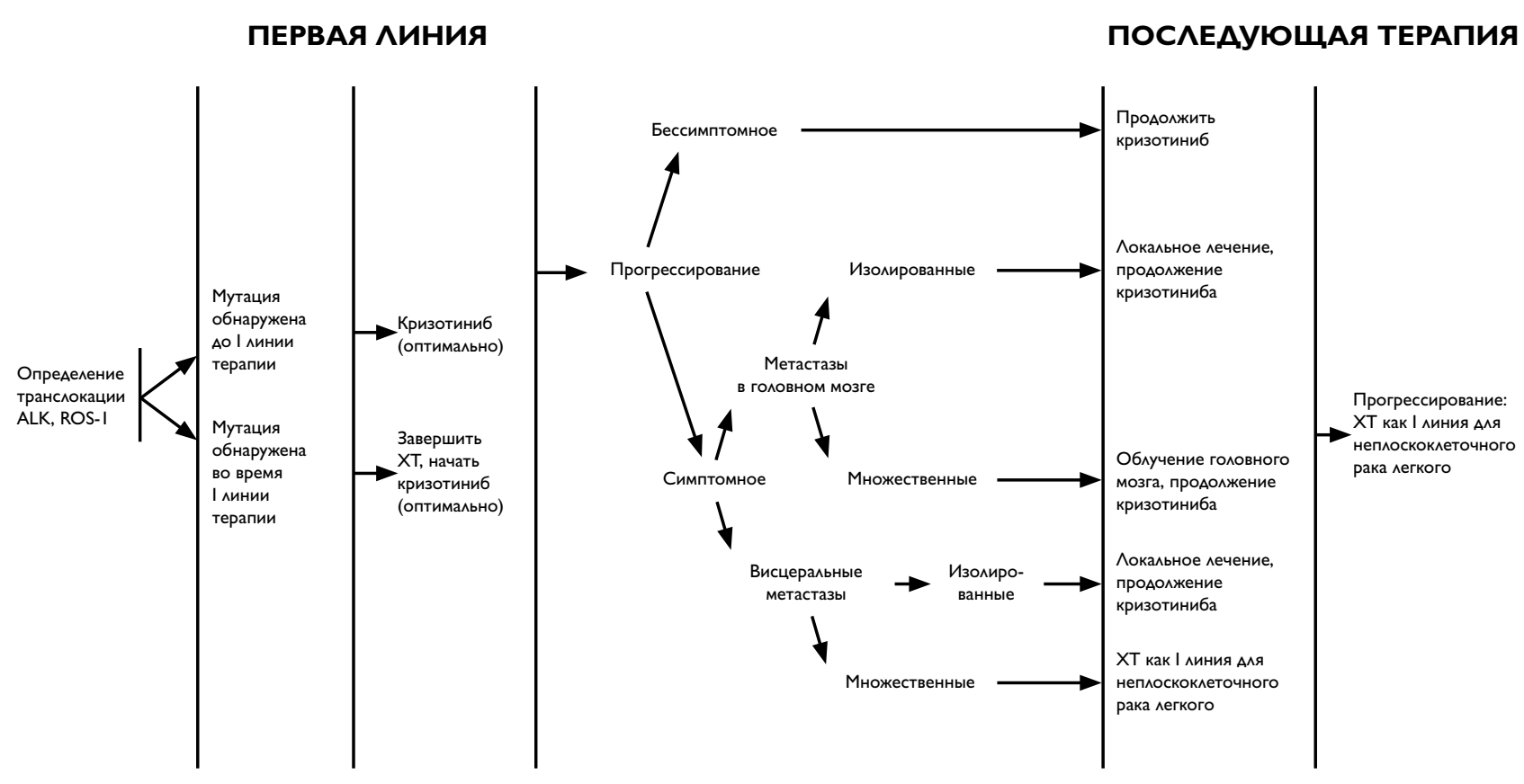

